\title{
A comparative, correlate analysis and projection of global and regional life expectancy, healthy life expectancy, and their GAP: 1995-2025
}

\author{
Xinxi $\mathrm{CaO}^{1 *}$, Yabing $\mathrm{Hou}^{1 *}$, \\ Xinyu Zhang ${ }^{1}$, Chenjie $\mathrm{Xu}^{1}$, \\ Peng $\mathrm{Jia}^{2}$, Xiaomin Sun ${ }^{3}$, Li \\ $\mathrm{Sun}^{4}$, Ying $\mathrm{GaO}^{5}$, Hongxi Yang ${ }^{1,6}$, \\ Zhuang Cui ${ }^{1}$, Youfa Wang ${ }^{3}$, \\ Yaogang Wang ${ }^{1}$ \\ ${ }^{1}$ School of Public Health, Tianjin Medical \\ University, Tianjin, China \\ ${ }^{2}$ Department of Earth Observation Sci- \\ ence, Faculty of Geo-information Science \\ and Earth Observation (ITC), University \\ of Twente, Enschede, Netherlands \\ ${ }^{3}$ Global Health Institute, Xi'an Jiaotong \\ University Health Science Center, Xi'an, \\ Shanxi, China \\ ${ }^{4}$ Nursing Laboratory Center, Tianjin Medi- \\ cal University, Tianjin, China \\ ${ }^{5}$ Health Management Centre, Tianjin Med- \\ ical University General Hospital, Tianjin, \\ China \\ ${ }^{6}$ Department of Biostatistics, Yale School \\ of Public Health, Yale University, New \\ Haven, Connecticut, USA \\ * Joint first authorship.
}

\section{Correspondence to:}

Youfa Wang, PhD, MD

Global Health Institute

Xi'an Jiaotong University Health Science Center

Xi'an

Shanxi, 710061

P R China

youfawang@gmail.com

Yaogang Wang, PhD, MD

School of Public Health

Tianjin Medical University

Tianjin, 300070

P R China

wyg@tmu.edu.cn
Background Life expectancy (LE) and healthy life expectancy (HALE) are indicators measuring the national health level. GAP is the difference between them. This study systematically analyzed and projected LE, HALE, and GAP across global regions from 1995 to 2025.

Methods We obtained the data of 195 countries/regions on their LE, HALE, and influencing factors from 1995 to 2017. We compared the overall changes of LE, HALE, and GAP. Multiple linear regression analysis examined relationships among LE, HALE, GAP, and the associated factors. Using the Autoregressive Integrated Moving Average (ARIMA) model, we projected trends in LE, HALE, and GAP for 2017-2025.

Results During 1995-2017, LE, HALE, and their GAP in 195 countries/regions in the world showed overall increasing trends. Global average LE increased from 66.20 to 72.98 years, HALE from 57.59 to 63.25 years, and GAP from 8.62 to 9.72 years. LE and HALE in North America, Europe, and Australia were generally higher, while Africa had the lowest rates. Females' LE, HALE, and GAP were all higher than males', but females' growth rates of LE and HALE were lower. Different factors were included to project LE, HALE, and GAP, respectively, and prediction results showed that approximately 18\% of the 195 countries/regions might achieve improved LE and HALE and lower GAP.

Conclusions LE, HALE will likely continue to increase in most of countries and regions worldwide in the future and GAP will further expand. While striving to improve LE and HALE, more attention needs be made to reduce GAP and improve quality of life.

With the socioeconomic development in many countries and regions worldwide, health policies and health care technologies are constantly improving, and life expectancy (LE) is increasing in most countries and regions [1]. The World Health Organization (WHO) has called for more attention to healthy life expectancy (HALE), but the focus was only on LE as early as 1997 [2]. Both LE and HALE are indicators that reflect the health status of a population. The GAP between LE and HALE can directly reflect the unhealthy survival time of a population, but there is scant research discussing GAP. Improving quality of life and decreasing unhealthy survival time while prolonging life is a goal for all countries [3].

LE is the most commonly used indicator to assess population health [4], and socioeconomic development and health care services are important factors affecting LE [5]. However, LE cannot fully reflect the quality of life. HALE, a bet- 
ter indicator of comprehensive population health and the quality of life [6-8], is defined by the Global Burden of Disease (GBD) studies as "the number of years that a person at a given age can expect to live in good health, taking into account mortality and disability" [9].

Many studies have referred to the changing trends and influencing factors in either LE or HALE [10]. Some studies have mentioned the gap between LE and HALE and called the indicator LE-HALE [11], but there are few in-depth analyses of the GAP, GAP focuses on revealing the unhealthy survival time of the population and is interpreted as the average number of years of healthy life lost to poor health, which is non-fatal disability. Raising LE and HALE and narrowing GAP are the goals of the global health field [3]. It is important not only to focus on the value of the changes in GAP, but also to combine LE and HALE to explore the health changes within each country.

Thus this study systematically studied LE, HALE, and GAP in 195 countries and regions from 1995 to 2017. We also projected the future trends in LE, HALE, and GAP for 2017-2025. Our finds may help design future national health policies.

\section{METHODS}

\section{Data sources}

We obtained the data for 195 countries and regions on their LE, HALE, and influencing factors for 19952017 from Global Burden of Disease (GBD), World Health Organization (WHO), and World Bank, and some from the official statistics websites. We computed GAP from LE and HALE (GAP = LE-HALE) and calculated the health loss rate (RATE, RATE = GAP/LE). Detailed data were shown in Table S1 in the Online Supplementary Document).

\section{Statistical analysis}

Descriptive analysis: We described the overall changes in LE, HALE, and GAP from 1995 to 2017, and by geographical distribution, economic level, and gender. We explored special outliers in different countries and years and explained the possible reasons for outliers.

Multiple linear regression analysis: Using multiple linear regression analysis, we explored the relationships among the factors with LE, HALE, and GAP from 1995-2012. Considering the social, economic, environmental, and disease factors, we included 15 influencing factors in our models.

Time series forecast analysis: We used the autoregressive integrated moving average (ARIMA) model to project LE, HALE, and GAP. The ARIMA model regarded it as a random sequence and used a mathematical model to approximately describe the sequence. Once this model was identified, future values could be predicted from the past and present values of the time series.

Statistical analyses: All statistical analyses were performed using IBM SPSS Statistics (V22.0) (IBM, Armonk, NY, USA). Statistical significance was evaluated at the 0.05 level.

\section{RESULTS}

\section{Overall changes of LE in global regions, 1995-2017}

From 1995 to 2017, approximately 95\%, 96\%, and 97\% of the 195 countries and regions had LE, HALE, and GAP showing an increasing trend (Figure 1). Global average LE increased from 66.20 in 1995 to 72.98 years in 2017, HALE increased from 58.12 to 62.96 years, and GAP increased from 8.52 to 9.33 years.

In 1995, the five countries with the highest LE were Andorra (80.45 years), Japan, Sweden, Switzerland, and Iceland; the five countries with the lowest LE were Rwanda (44.58 years), Malawi, the Central African Republic, Zambia, and Uganda. The five countries with the highest HALE were Japan (70.03 years), Andorra, Spain, Sweden, and Singapore. The five lowest countries were Rwanda (39.16 years), the Central African Republic, Malawi, Uganda, and Zambia, the difference between maximum and minimum LE is 30.87 years.

In 2017, the five countries with the highest LE were Singapore (84.79 years), Japan, Switzerland, Italy, and Kuwait, while the five with the lowest LE were the Central African Republic (51.87 years), Lesotho, 


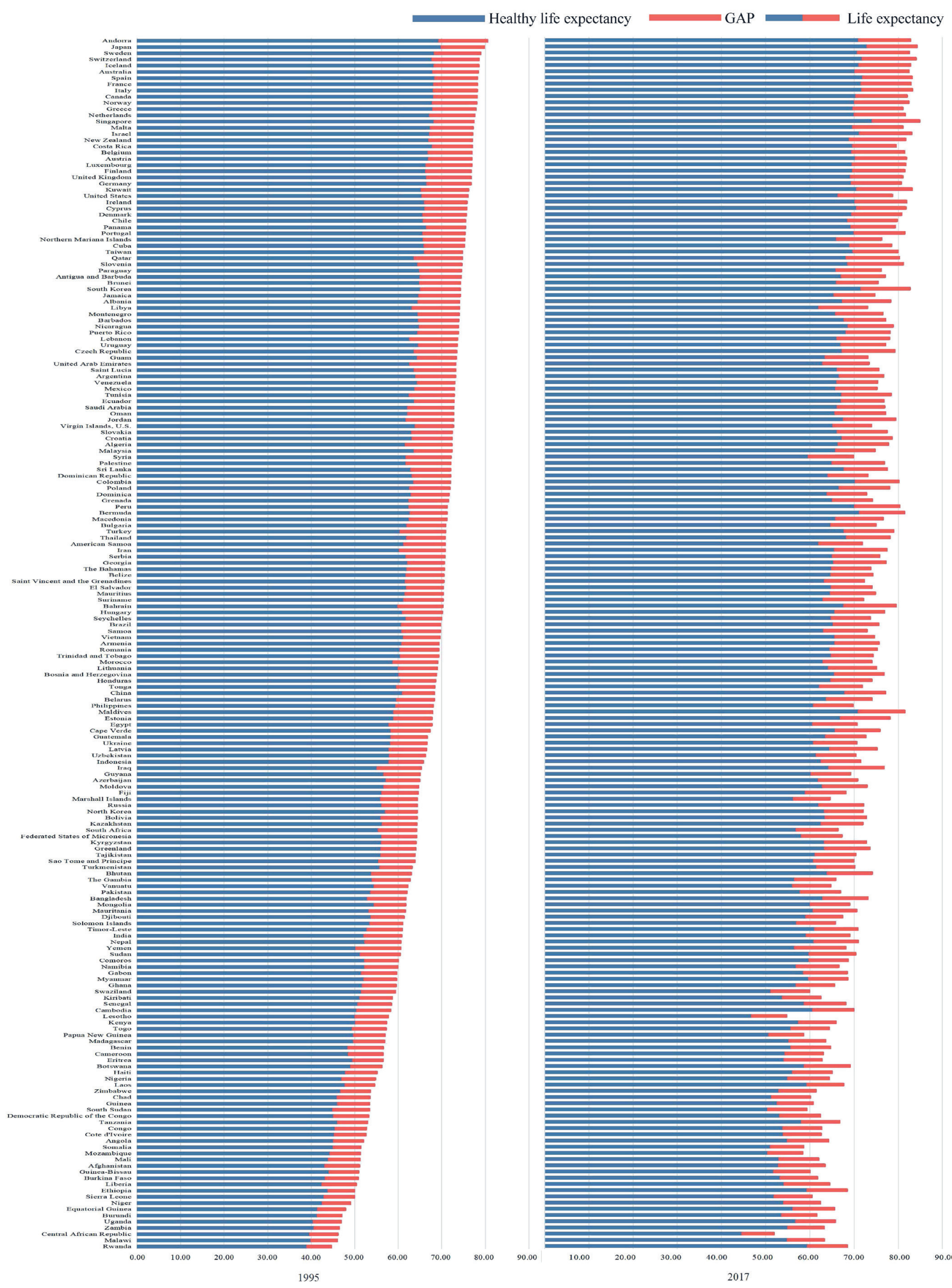

Figure 1. Trends of global and regional LE, HALE, and GAP, 1995 and 2017. 
Papua New Guinea, Mozambique, and Somalia. the difference between maximum and minimum LE is 32.92 years.

The five countries with the highest HALE were Singapore (74.22 years), Japan, Spain, Switzerland, and Italy; the five countries with the lowest HALE were the Central African Republic (44.75 years), Lesotho, South Sudan, Mozambique, and Papua New Guinea, the difference between maximum and minimum HALE is 29.47 years.

In 1995, China, North Korea, Seychelles, and Mongolia had the lowest RATE values. In 2017, the five countries/regions with the lowest were US Virgin Islands, China, Malaysia, the Bahamas, and Vietnam. From 1995 to 2017, the compound annual growth rates of GAP in Rwanda, Georgia, Botswana, Equatorial Guinea, and Ethiopia were the highest, while the United States, France, Canada, the United Kingdom, and Cyprus maintained relatively lower growth rates. Besides, the RATE in 68\% of the countries and regions increased.

\section{Geographical and economic distribution characteristics of LE, HALE, and GAP}

Geographically, LE in North America, Europe, and Australia was generally higher than that of other regions, but in Africa, it was relatively low. The top five countries with the highest compound annual growth rate of LE were Rwanda, Uganda, Ethiopia, Equatorial Guinea, and Malawi (Figure 2, Panel A). HALE in North America, Europe, and Australia was generally higher than in other regions, Africa and India in particular had lower HALE (Figure 2, Panel B). RATE in the United States, Australia, India, and Africa was large but relatively small in China and Central Asia, especially the Chinese males' RATE is smaller (Figure 2, panel C).

Nationally, developed countries such as Japan, Singapore, and Australia maintained high LE and showed an increasing trend, while the average growth rates of LE were lower in most developing countries. Developed countries had higher HALE than most developing regions, while HALE in China and Brazil showed a large increase from 1995 to 2017. In high- and low-income countries, RATE was large, while in the middle-income countries, RATE was smaller.

\section{Gender difference of LE, HALE, and GAP}

There were some gender differences. Males' LE was lower than females, but their annual growth rate was faster than females in 121 countries and regions. The gender difference in LE in most countries and regions showed a decreasing trend, but it increased in Lesotho, Syria, Swaziland, and Guam. In terms of gender, female' HALE was higher than males' while the female growth rates in more than half of the countries and regions were lower than the male. In most countries, the gender differences in HALE decreased, but widening gender differences persisted in Macedonia, Finland, Jordan, Mauritius, and Lesotho. In terms of gender, female GAP and RATE were both higher than male, especially in North America, Europe, and Africa. Overall, 59 countries and regions showed an increasing trend in female RATE and 67 countries and regions in male, while the growth rates of female GAP were lower than male in most countries and regions.

\section{Countries with special LE, HALE, and GAP}

From 1995 to 2017, LE and HALE in most countries increased rapidly. In particular, Rwanda's LE showed a sustained rapid rise, increasing from 44.58 years in 1995 to 68.46 years in 2017. HALE rising from 39.16 to 59.65 years.

In general, LE had a pronounced stratification around the age of 65 years. In most high-income and middle-high-income countries and regions, LE was above 65 years, while LE in low-income and middle-low-income countries was generally under 65 years. In general, HALE had a pronounced stratification around the age of 55 years. In most high-income and middle-high-income countries and regions, LE was above 55 years, while LE in low-income and middle-low-income countries was generally under 55 years.

Compared to 1995, LE in 2017 showed a decreasing trend in Guam, Syria, Libya, and Lesotho. Lesotho had the greatest decline in LE, decreasing from 57.68 years in 1995 to 54.66 years in 2017 (Figure 3, Panel A). However, in some countries, HALE showed a decreasing trend (Figure 3, Panel B). In 2017 , HALE in Guam, Swaziland, Syria, Lesotho, and Libya were all lower than in 1995. GAP decreased in some countries and regions, for example GAP of Jamaica, Marshall Islands, Saint Lucia, Syria, United Arab Emirates, and US Virgin Islands in 2017 were lower than that in 1995 (Figure 3, Panel C), GAP decreased in Syria by $9.59 \%$, in Lesotho by $12.88 \%$, and in Jamaica by $3.11 \%$. 


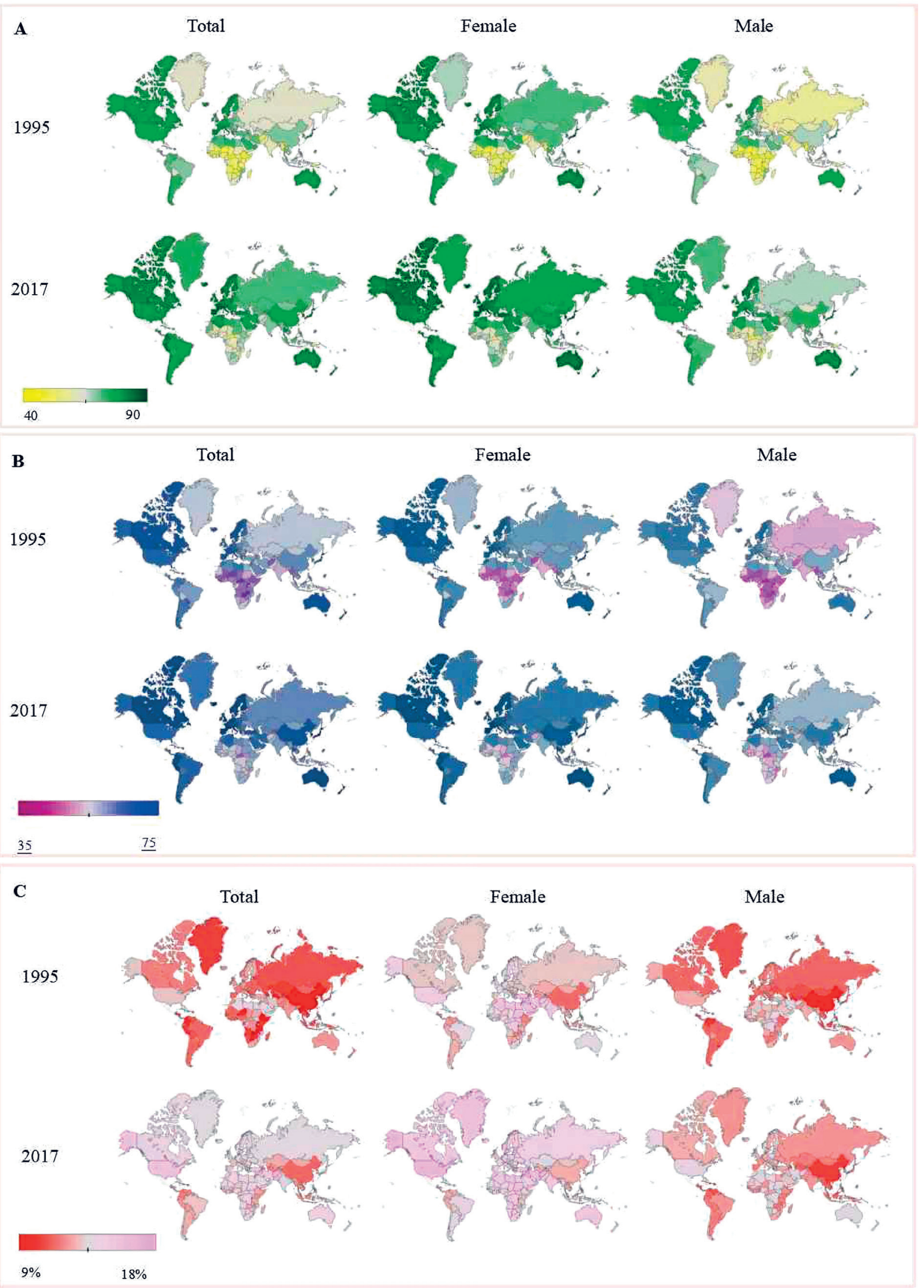

Figure 2. Changes in life expectancy (LE), healthy life expectancy (HALE) and RATE (GAP/LE) between 1995 and 2017 in different countries and regions and gender differences. Panel A. Changes in life expectancy between 1995 and 2017 in different countries and regions and gender differences. Panel B. Changes in healthy life expectancy between 1995 and 2017 in different countries and regions and gender differences. Panel C. Changes in RATE between 1995 and 2017 in different countries and regions and gender differences. GAP - difference between LE and HALE. 

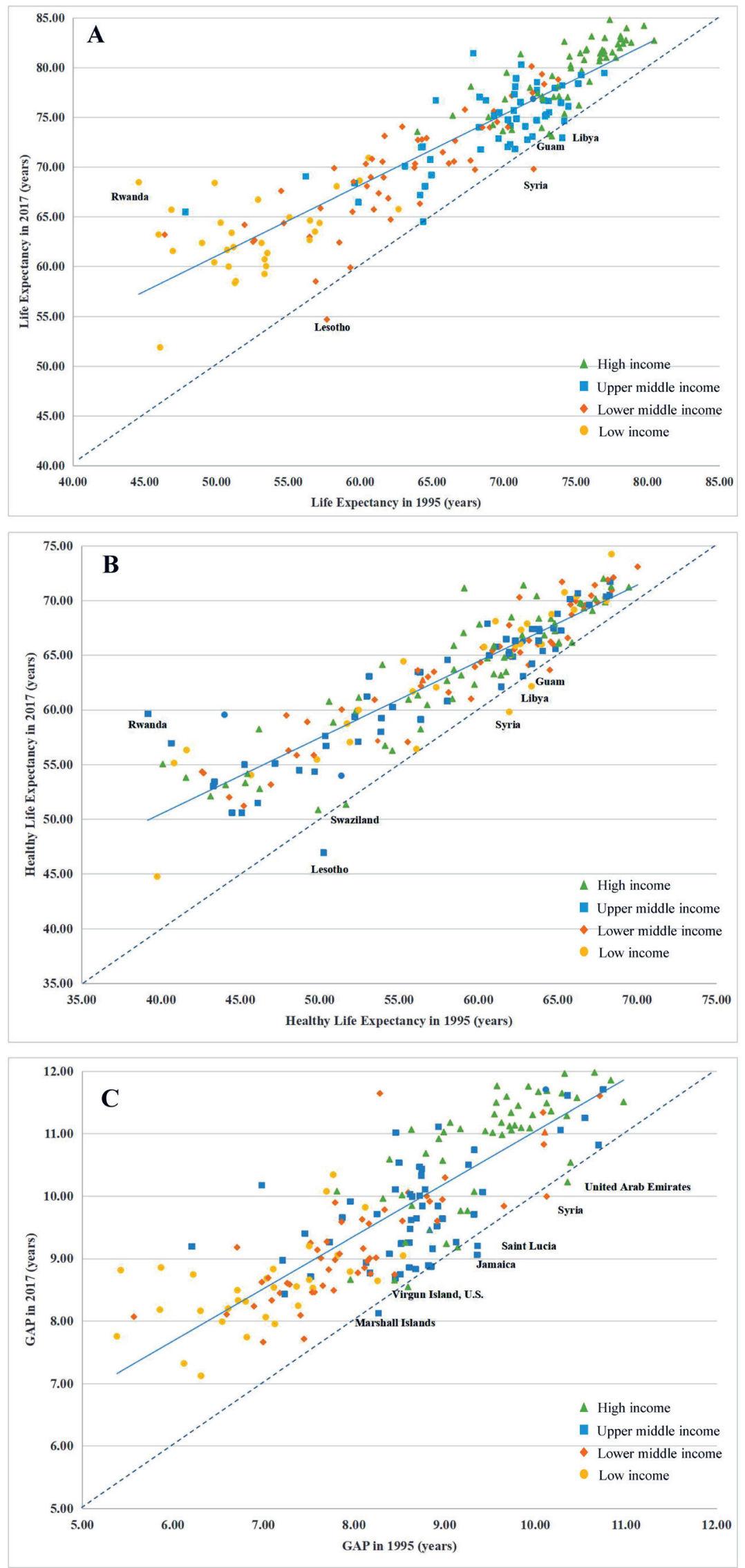

Figure 3. Comparison of global and regional life expectancy (LE), healthy life expectancy (HALE) and their difference (GAP) between 1995 and 2017. Panel A. Comparison of life expectancy, 1995 and 2017. Panel B. Comparison of healthy life expectancy, 1995 and 2017. Panel C. Comparison of GAP, 1995 and 2017. 
Some countries and regions showed significant turning points during 1995-2017 (Figure 4, Panel A). Congo and Guam in 1997, Honduras in 1998, Indonesia and Eritrea in 1999, Myanmar in 2008, Haiti in 2010, and Libya in 2011 all had sharp declines in LE, while LE in North Korea increased from 63.59 years in 2002 to 69.97 years in 2003. The development of HALE had similar turning points with LE (Figure 4, Panel B). For example, in 2009, Haiti's HALE was 52.35 years, while it was 29.50 years in 2010. HALE had a decline of $43.64 \%$. The increase in the mortality rate caused by emergencies resulted in a decrease in both LE and HALE during this year. GAP showed some turning points in some countries and regions (Figure 4, Panel C). For example, in 2009, Haitis GAP was 7.64 years, while it was 2.15 years in 2010 , a decline of $71.86 \%$.

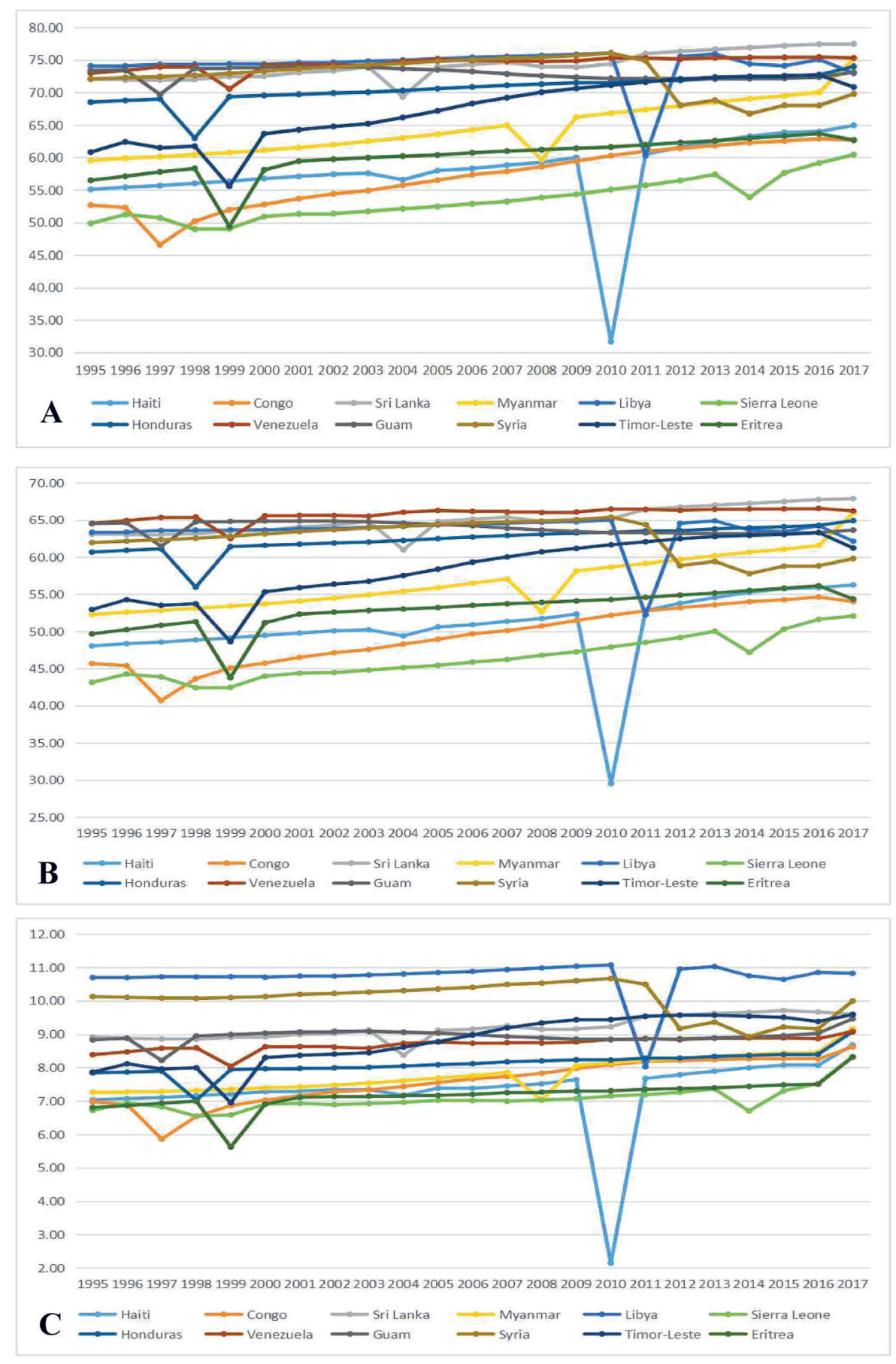

Figure 4. Countries/regions with special turning points of life expectancy (LE), healthy life expectancy (HALE) and their difference (GAP). Panel A. Countries/regions with turning points of life expectancy. Panel B. Countries/ regions with turning points of healthy life expectancy. Panel C. Countries/regions with turning points of GAP. 


\section{Multiple linear regression analysis of factors associated with LE, HALE, and GAP}

Fifteen factors were included in multiple linear regression analysis for these outcomes using the 19952012 data, respectively. Among them, three were statistically significant for LE $(P<0.05)$, Urbanization, TFR (the total fertility rate), and HFPerc (percentage of population with improved facilities). Four factors were statistically significant for HALE $(P<0.05)$, which were Urban, TFR, HFPerc, and incidence of chronic diseases. Only urbanization was statistically significant for GAP $(P<0.05)$.

\section{Projections of LE, HALE, and GAP in global regions, 2017-2025}

Based on multiple linear regression analysis, we projected LE, HALE, and GAP for 2017 to 2025 in 149 countries and regions, which had the needed data (Table 1; see Table S2, S3, S4 in the Online Supplementary Document for the full projected results).

According to the projected trends, we divided the results into eight scenarios (Figure 5). The results showed that the largest proportion is $71.8 \%$, indicating that the countries and regions with LE, HALE and GAP increase in the future still account for the majority. An ideal state of population health meant that the countries and regions should have higher LE, higher HALE, and lower GAP. The projected results showed that 27 (18.12\%) countries and regions might reach this ideal state in the future. Some developed countries such as Switzerland would have slightly lower GAP along with higher LE and HALE, so did developing countries such as Belarus.

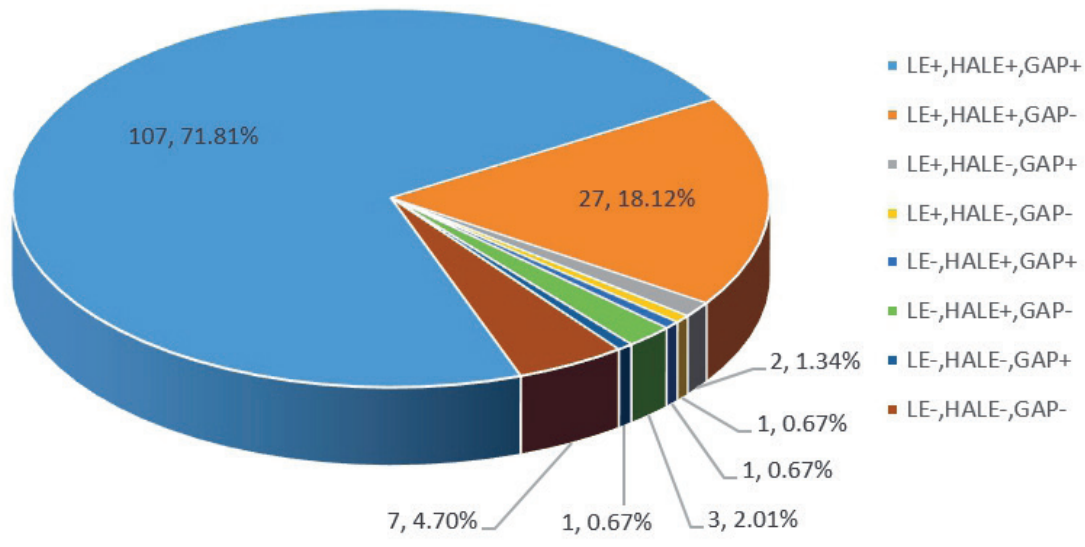

Figure 5. Eight scenarios of prediction of life expectancy (LE), healthy life expectancy (HALE) and their difference (GAP).

The most unsatisfactory state meant decreasing LE and HALE with increasing GAP. The projection suggested that 1 country might remain in this unsatisfactory state: Botswana. In Botswana, the projected LE would decrease by 1.46 years from 65.97 (95\% confidence interval $(\mathrm{CI})=65.37-66.56)$ years in 2017 to 64.51 (95\% CI=54.62-74.39) years in 2025. Its HALE would decrease from 57.14 ( $95 \% \mathrm{CI}=56.71$ 57.57 ) to 55.61 (95\% $\mathrm{CI}=49.55-61.68)$ years and GAP increase from 8.81 (95\% CI=8.58-9.04) to 10.23 (95\% CI $=6.31-14.15)$ years.

The projected results suggested that in Zambia, LE would continue to increase, while HALE would decrease, causing the continuous expansion of GAP in the future. LE in Zambia would increase from 59.36 (95\% CI =58.76-59.96) years in 2017 to 65.21 (95\% CI =56.08-74.34) years in 2025, HALE would decrease from $51.36(95 \% \mathrm{CI}=51.46-52.45)$ to 51.64 (95\% CI=43.25-60.03) years, and GAP would increase by 1.03 (from 7.29 to 8.32) years. However, countries such as the United States, Australia, Cyprus, and Turkey would have lower LE, HALE, and GAP in the future. In United States, LE would decrease from 78.84 (95\% CI $=78.68-79.00$ ) years in 2017 to 78.80 (95\% CI $=76.09-81.32$ ) years in 2025, HALE would decrease from 67.68 (95\% CI=67.56-67.80) to 67.55 (95\% CI=65.52-69.59) years, and GAP would decrease by 0.02 years. 


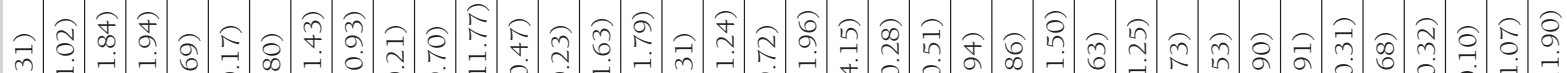
य 0 क

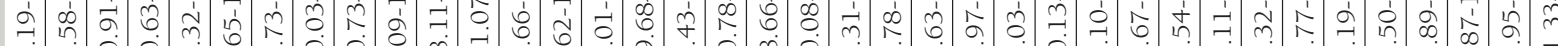

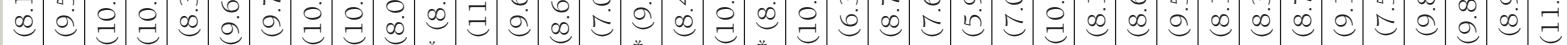

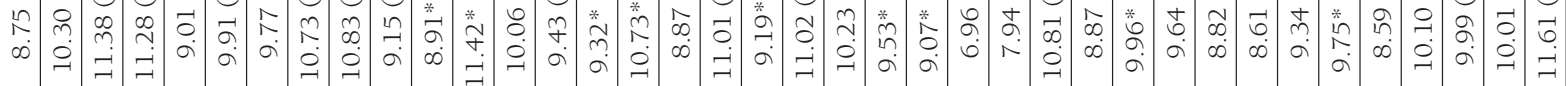

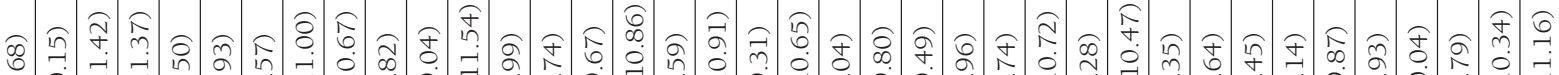

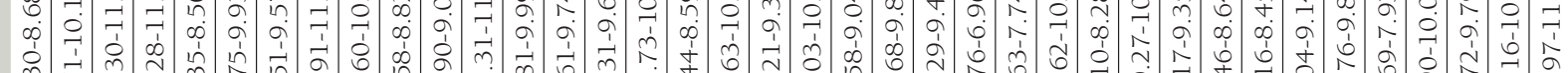

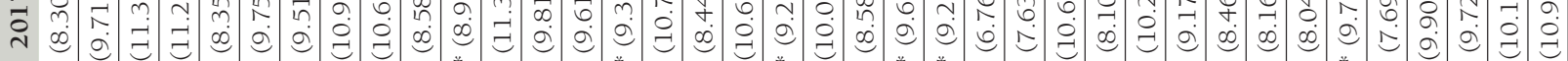

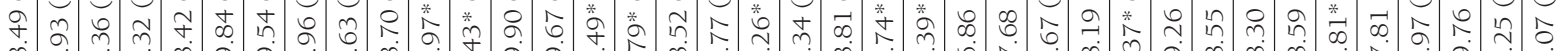

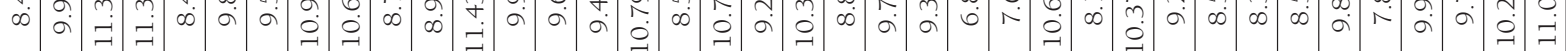

字品

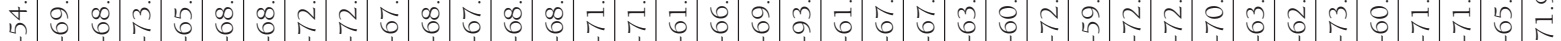

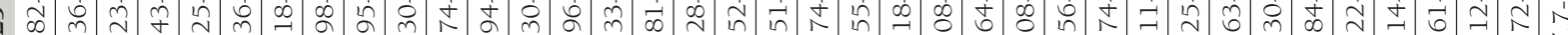

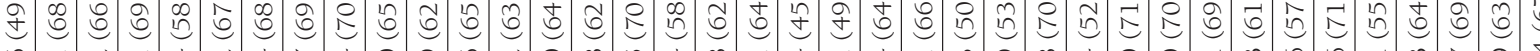

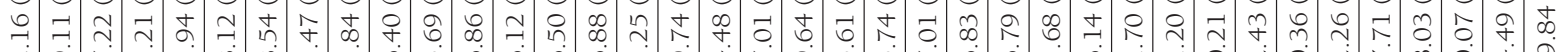

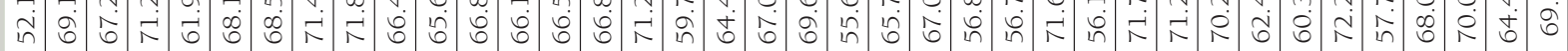

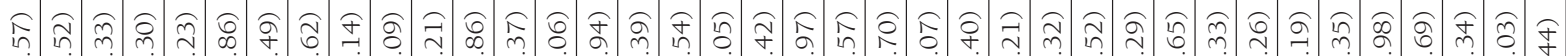

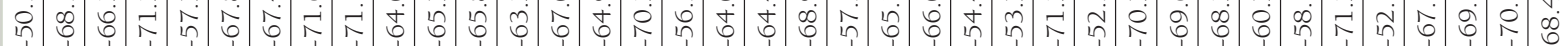

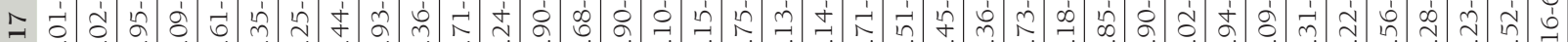

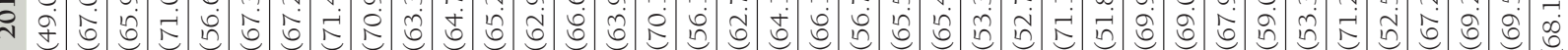

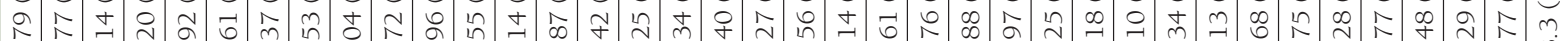

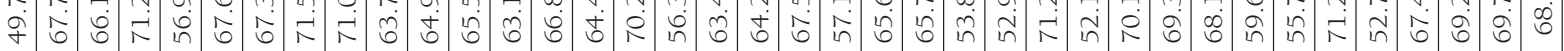

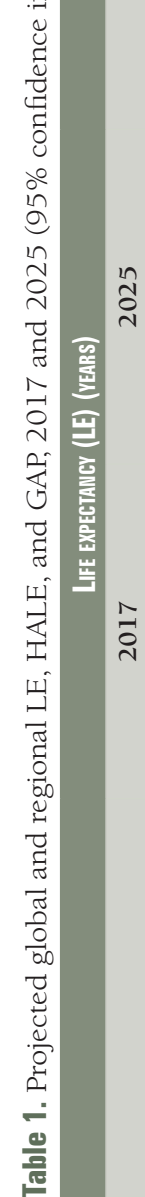

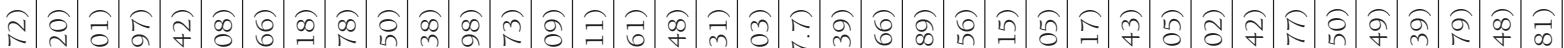

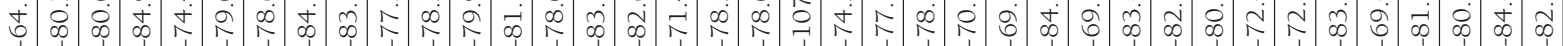

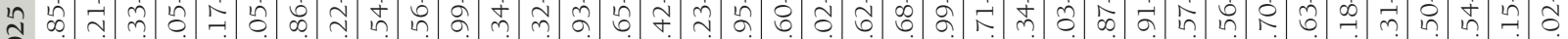

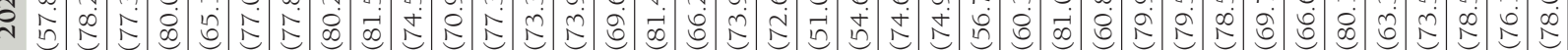

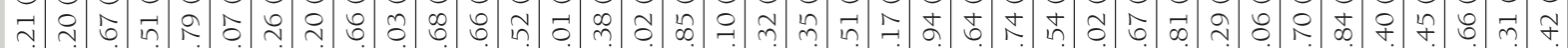

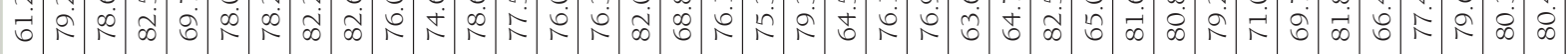

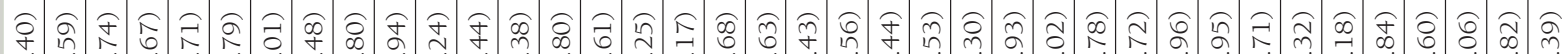

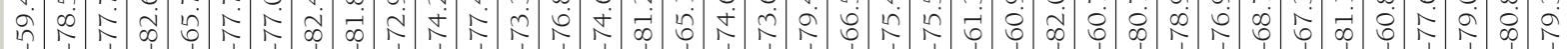

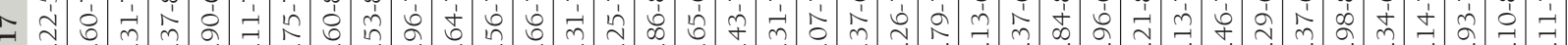

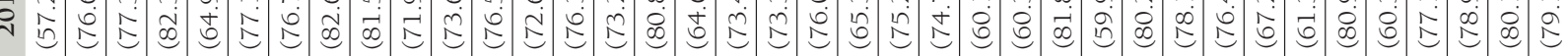

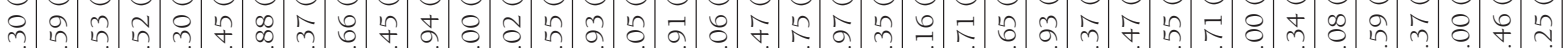

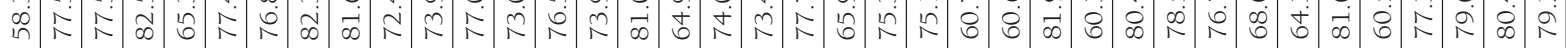




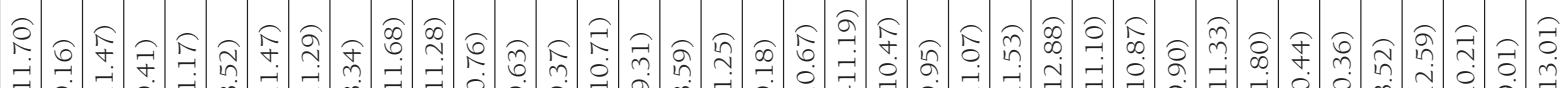

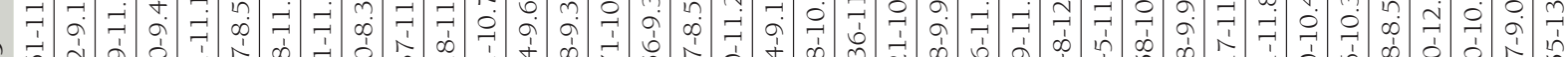

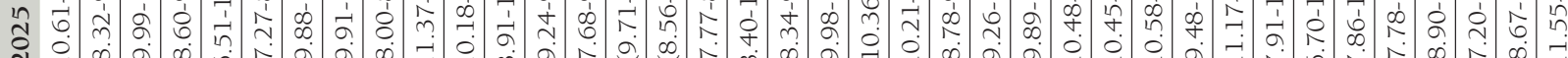
事

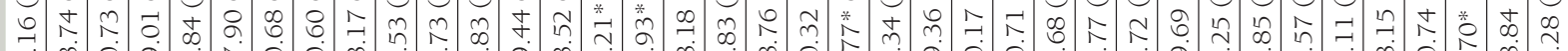

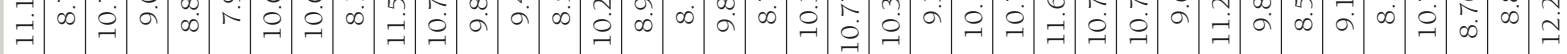

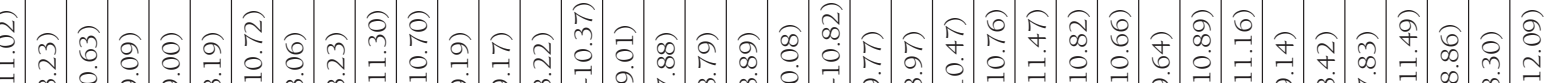

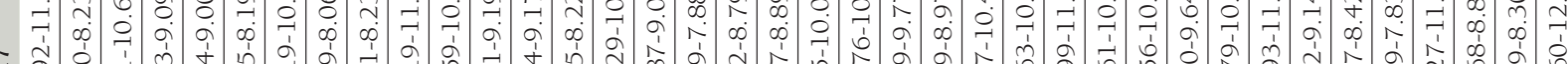

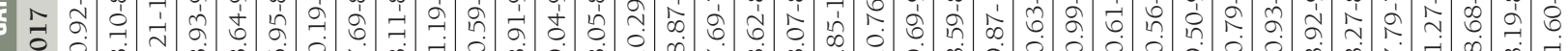

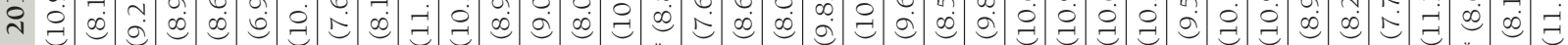

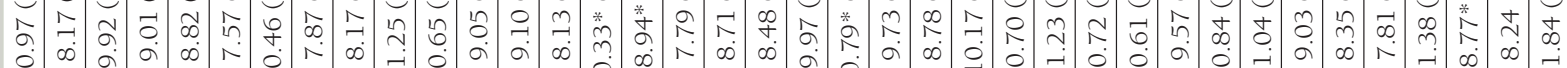

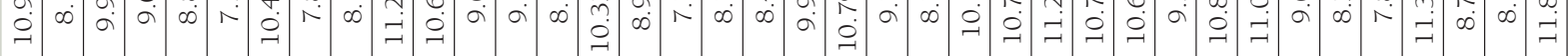

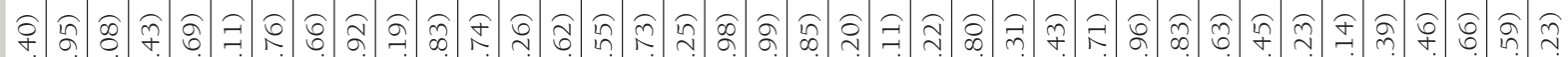

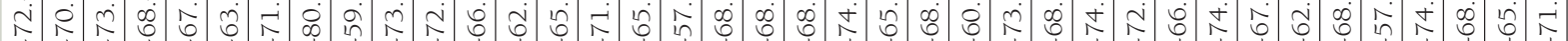

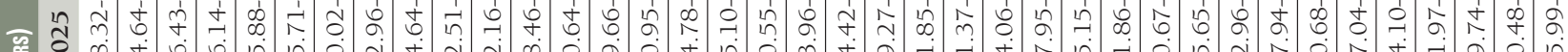
产 毘

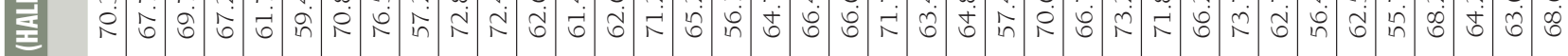

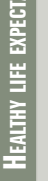

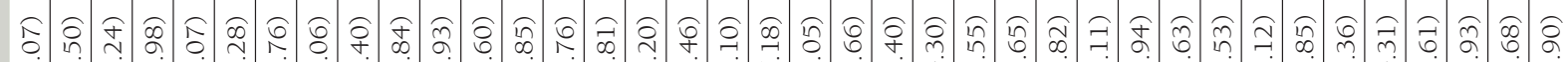
र

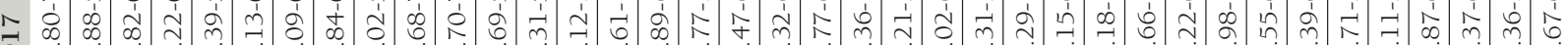
ᄀ $\begin{aligned} & 0 \\ & 0\end{aligned}$

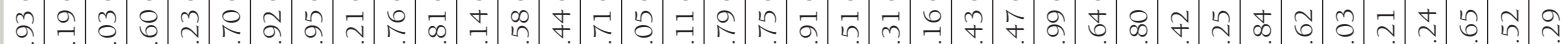

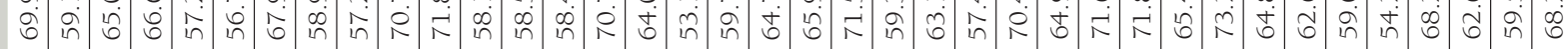

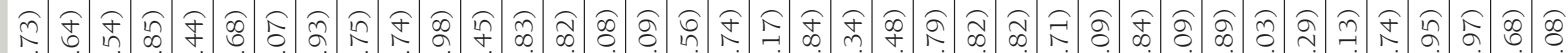

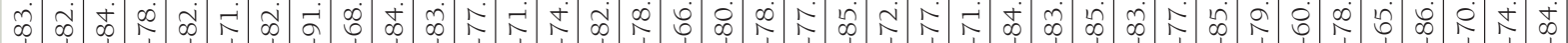

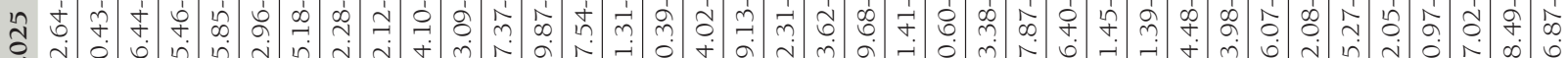

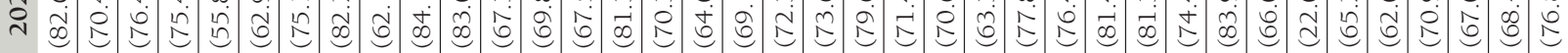

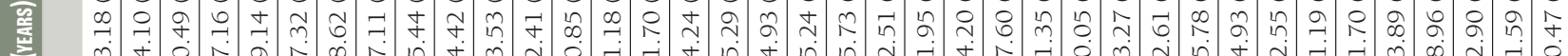

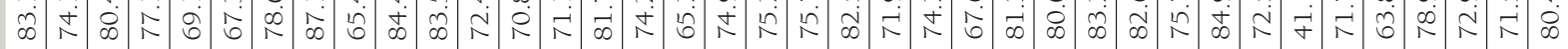

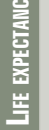

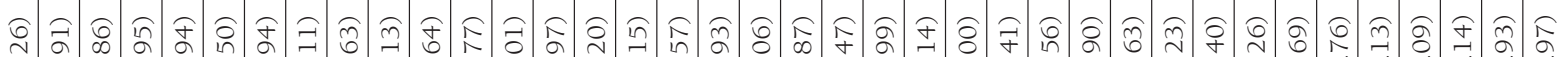

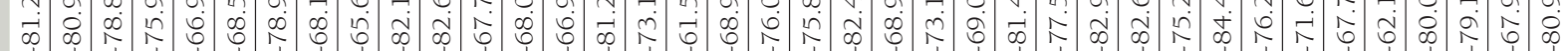

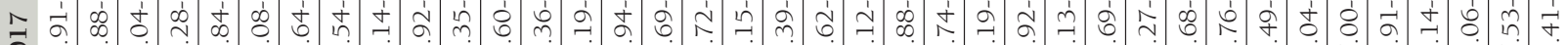

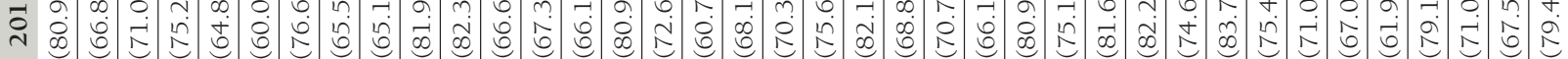

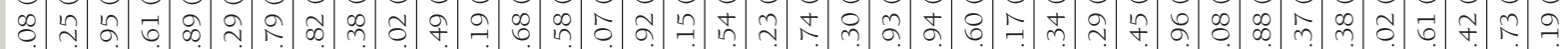

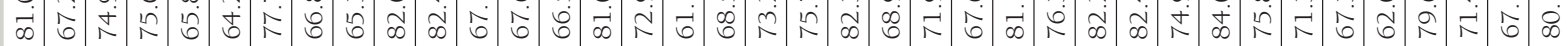

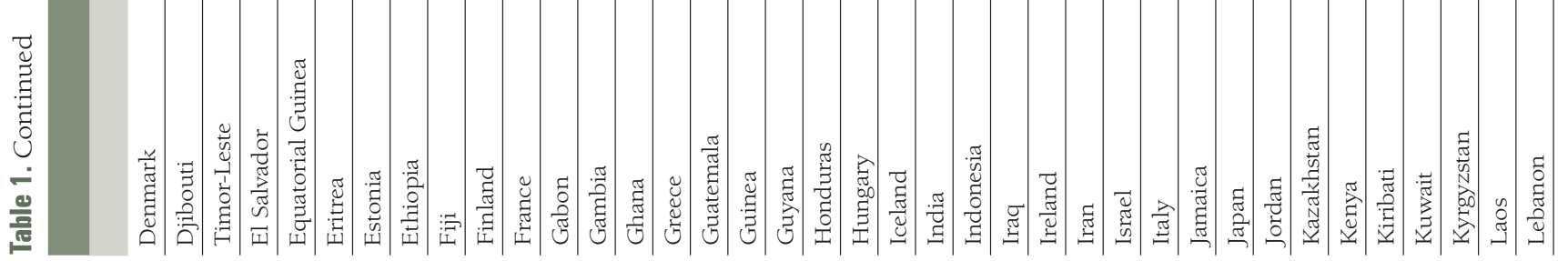




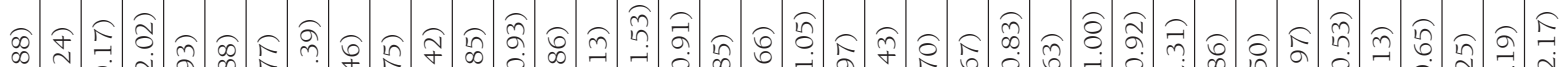

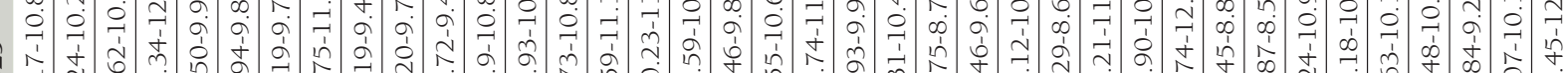

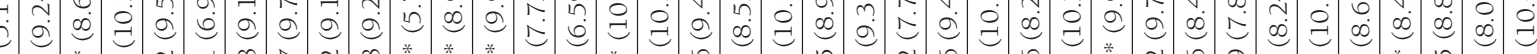

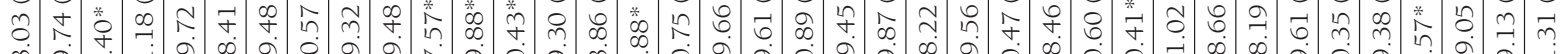

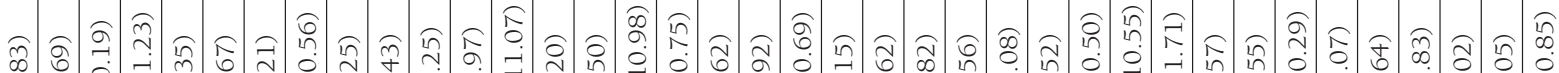
훙

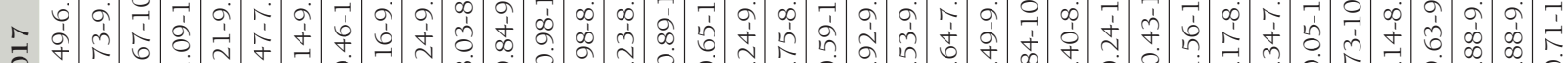

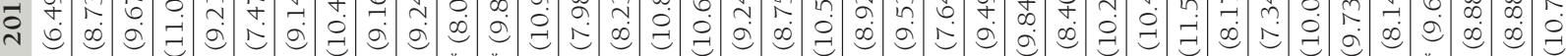

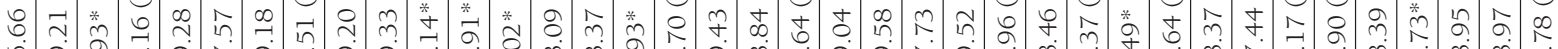

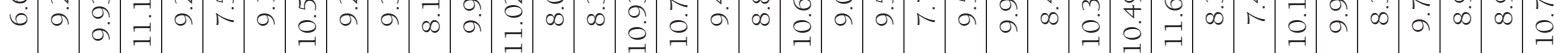

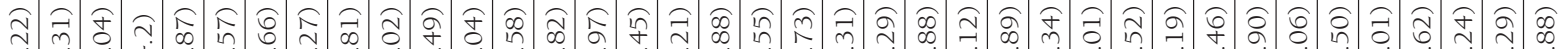

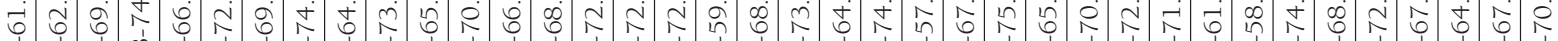

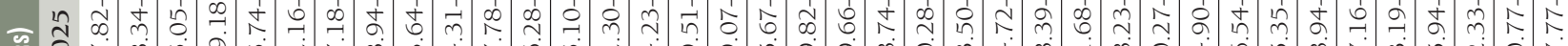

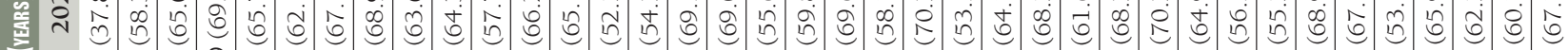

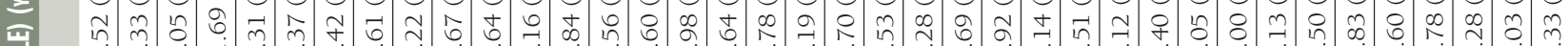

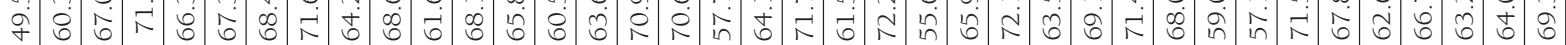

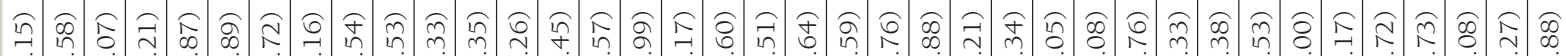

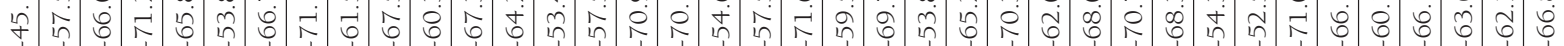

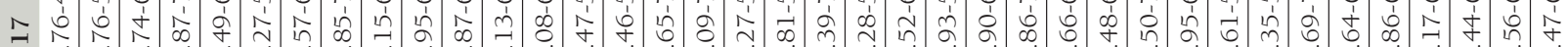

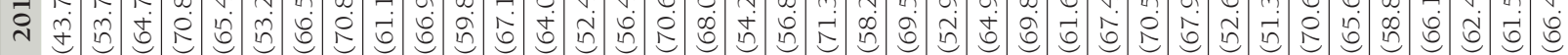

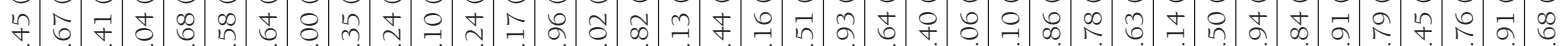

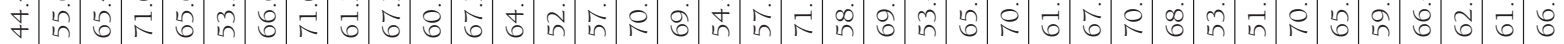

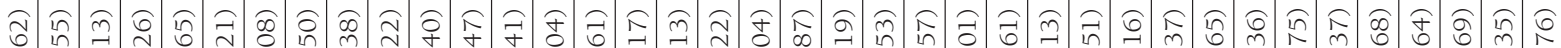

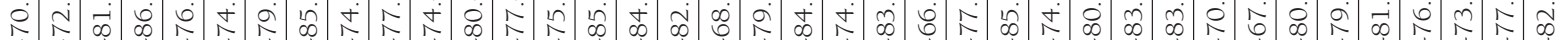

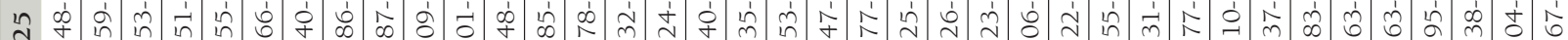

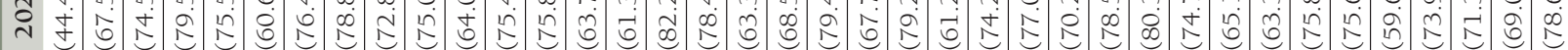

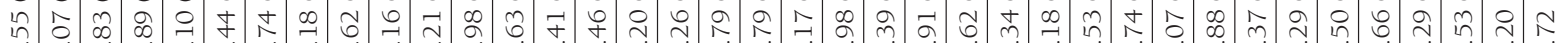

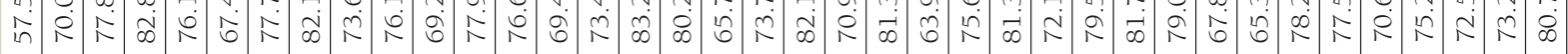

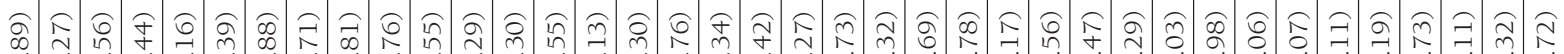

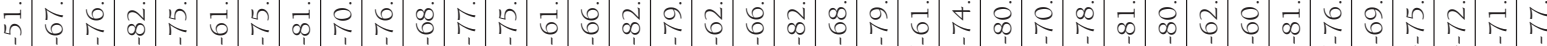

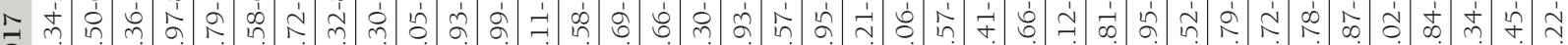

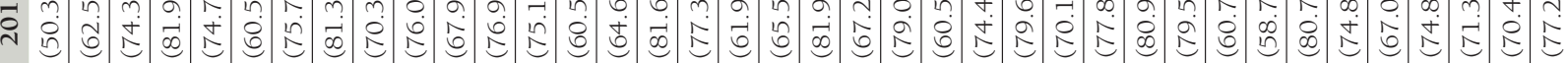

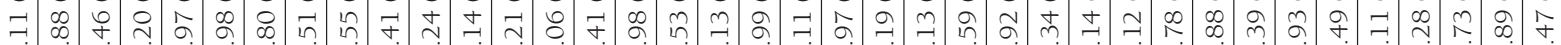

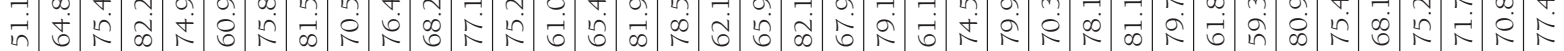
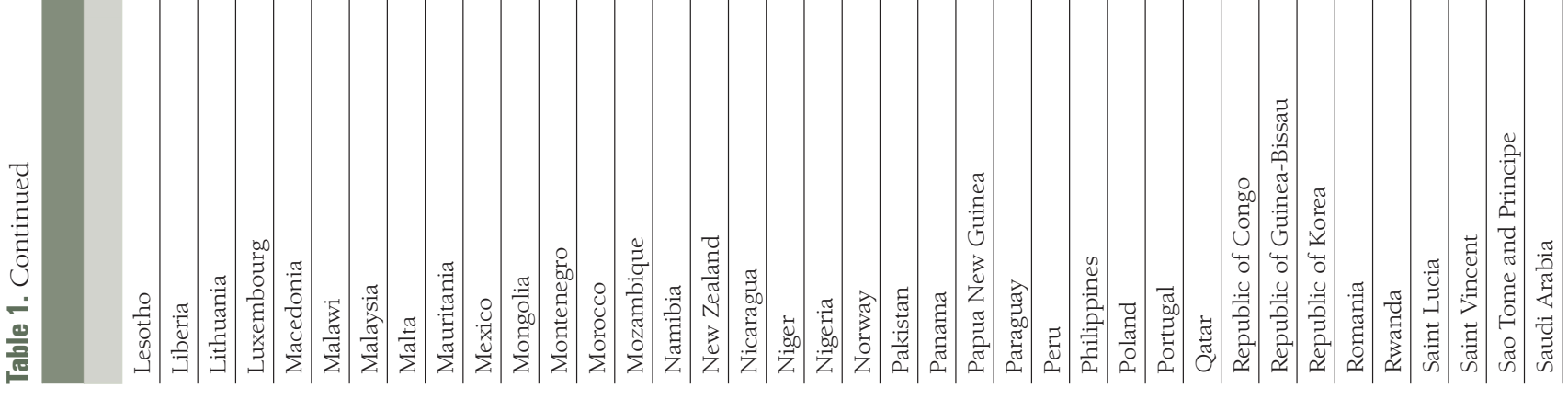


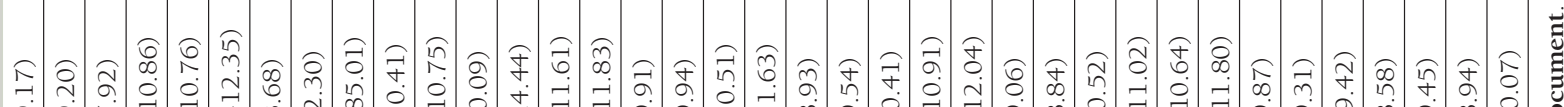

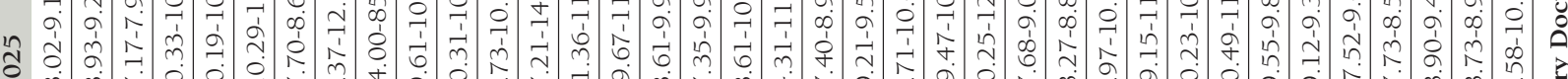

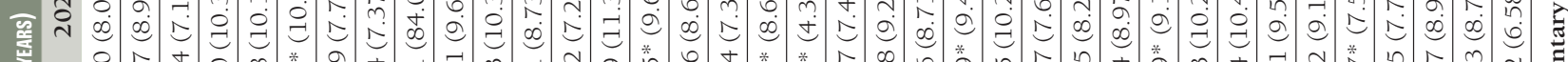
b.

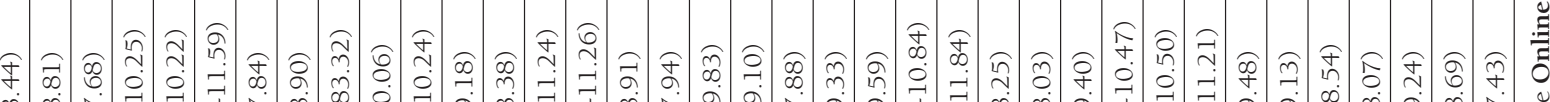

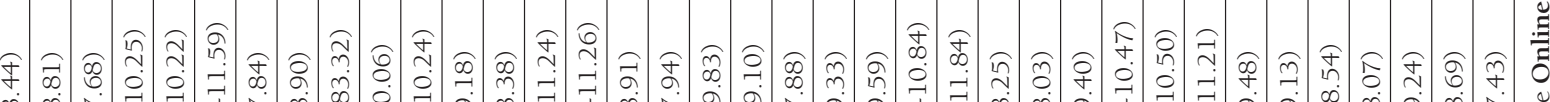
(1)

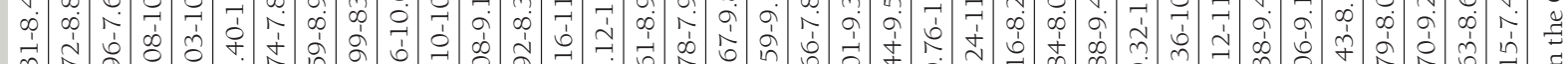

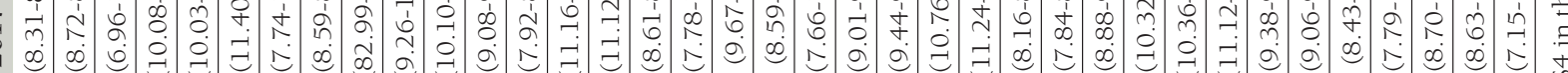

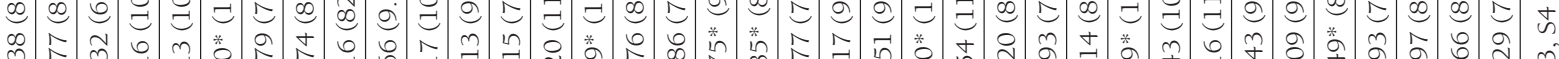

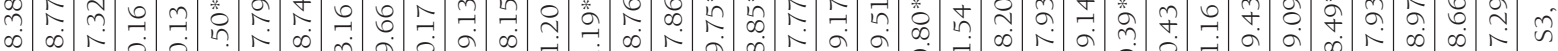

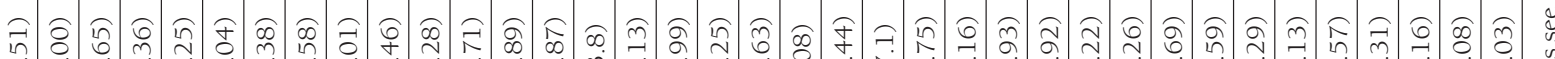
○一

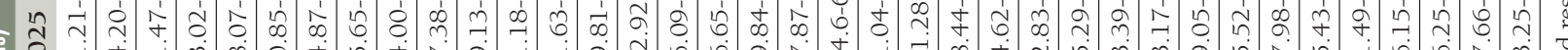

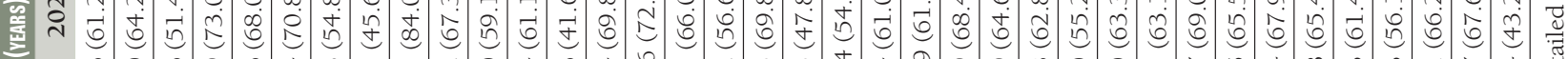

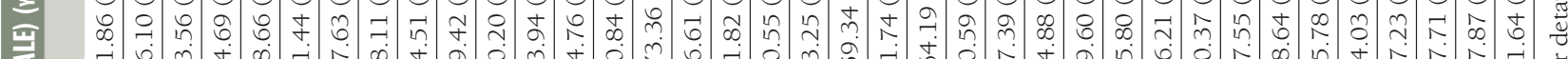
应

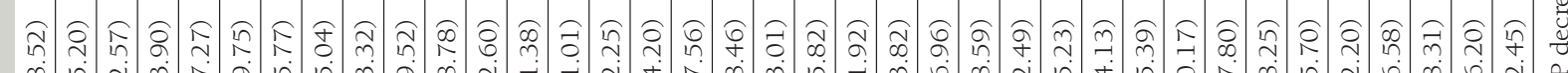
की

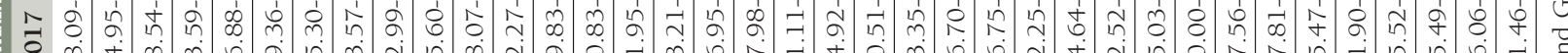

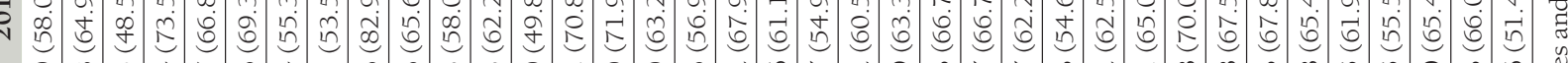

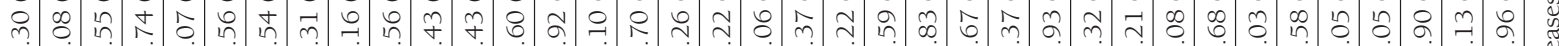

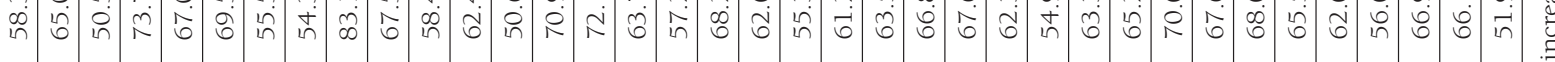

ง⿵门人

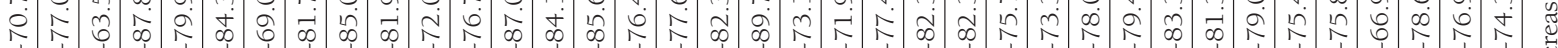

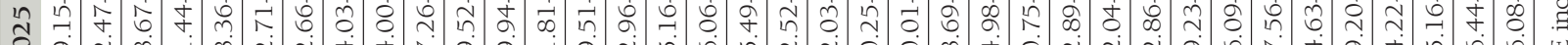
ป

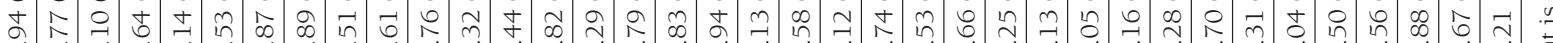

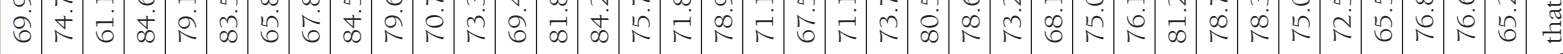

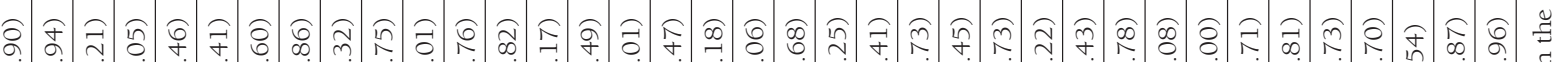

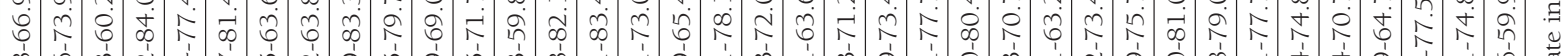
$=\overbrace{0}^{\circ}$

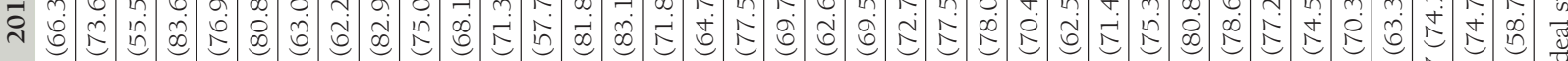

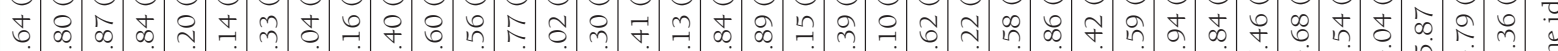

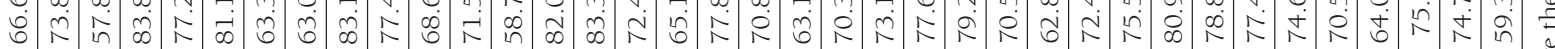
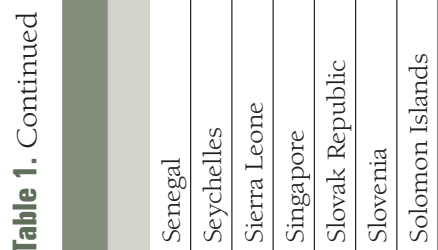

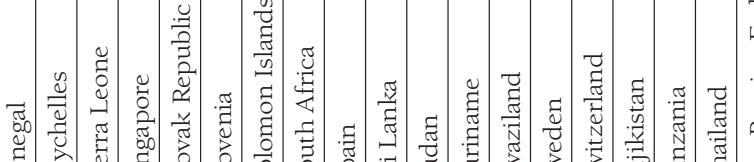

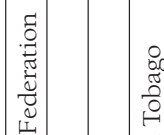

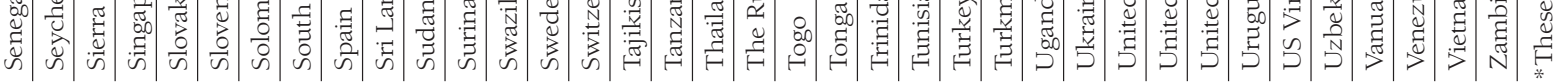


In general, in most countries/regions (about 72\%), LE, HALE and GAP would maintain an increasing trend, while in some regions, the growth rate of HALE was greater than that of LE, ie, GAP would decrease.

\section{DISCUSSION}

Our analysis showed that from 1995 to 2017, LE (95\%), HALE (96\%), and GAP (97\%) in most of the 195 countries and regions showed an overall increasing trend. LE, HALE, and GAP would continue to increase in the future. Some countries and regions might achieve an ideal state. The increasing LE and HALE indicated that the health status had improved worldwide in the past and would continue to improve in the future, but there were some considerable disparities among countries, some countries/regions seem to be left behind these improvements, and more attention is needed for these countries in the future.

LE and HALE showed an increasing trend in 186 out of the 195 (95\%) countries and regions, this was attributed to economic development that promotes improvements in medical services and the social environment. In most high-income and middle-high-income countries/regions, LE was above 65 years and HALE was above 55 years, the driving forces of higher LE and HALE in these countries/regions were mainly from national health policy reforms, welfare, and policies [12-16]. In low-income and low-middle-income countries, LE and HALE increased, but the growth was lower, especially the slower growth of HALE, which had led to further expansion of GAP. This might be due to improved coverage of infrastructure, security, and basic health services, and the promotion of basic health care for people, but the lack of further coverage of health facilities and technologies [17].

Both LE and HALE decreased in 4 countries and regions, Lesotho had the greatest decline. The main reasons for the reduction in these countries/regions were the outbreak of war and AIDS in these countries and regions. According to the United Nations' estimates, one-quarter of people in Lesotho carry HIV. In addition, HALE in Paraguay and Northern Islands also decreased. The decrease in HALE means that the quality of life of the population has not improved, and medical claims, medical insurance systems, and welfare policies in the health field are inadequate. The increase in GAP meant that the growth rate of LE was greater than that of HALE, this was largely due to changes in the spectrum of diseases, the prolonged survival of the sick population, and the growing aging of society, which intensified the global burden of disease. GAP in 4 countries and regions decreased. These regions' GAP decreased accompanied with LE and HALE increased during the last decade as medical advancements and breakthroughs in preventing HIV pediatric infections and mother-to-child transmission were widely implemented [18]. The absolute narrowing of the GAP did not mean that the health level of a country had reached the expected level. Only in the context of the common growth of LE and HALE, it could be meaningful to achieve the gap reduction.

Females' LE, HALE, GAP, and RATE were all higher than males' overall. Previous studies had shown that females tended to live longer and they had longer unhealthy survival time than males [19]. It is noteworthy that females paid more attention to their health than males; once females have symptoms of illness, they seek medical treatment more actively [20]. Compared with males, females gained a longer life expectancy free of major chronic diseases through adherence to a healthier lifestyle,such as no drinking and no smoking. While males bear more social stress and undertake more dangerous work. They tend to have unhealthier lifestyles, such as smoking and alcoholism.

Our analysis projected that 102 countries and regions (71\%), LE, HALE and GAP would increase in the future. For example, Canada will achieve a higher LE and HALE along with a little higher GAP. Canada has enacted a series of funds to explore, prevent, and control morbidity and mortality and established an area-based social-economic measure that is confirmed to strongly correlate with improving potential lifeyears lost and life expectancy [21]. Japan is another example with such good outcomes, thank to its good medical service factors and other non-medical factors such as its education and legislation systems, culture, community-based activities, and diet [22]. Japan's medical affordability, medical quality, and community participation were satisfactory, while human resources and the easing of the medical environment were unsatisfactory, so there was an urgent need to increase the number of health workers and improve the medical environment to reduce the further expansion of the GAP [10].

The increase in Singapore's GAP contributed to the transition of disease burden from high-mortality diseases such as infections to chronic conditions. Studies have shown that factors such as diabetes and obesity make Singaporeans more susceptible to chronic diseases and affect their quality of life [23,24]. In the United States, LE, HALE, and GAP will decrease further. This may be attributable to a high incidence of gun violence, automobile accidents, drug abuse, and a high average BMI, while the incidence of chronic 
diseases such as diabetes and cardiovascular disease is increasing [25]. The health care needs of people suffering from chronic diseases have increased [26]. Insufficient investment in health care costs and unreasonable utilization of the infrastructure remain important challenges to improving the health of the worldwide population in the future $[5,15]$.

Our study has some limitations. First, our analysis could not incorporate factors such as education and specific chronic diseases such as cardiovascular disease, hypertension, tobacco and alcohol use due to lack of data. The factors could affect LE, HALE, and GAP as well. Second, our projection model is an exploratory simulation of the trends of LE, HALE, and GAP. It is better suited for short-term predictions. The long-term predictions for the future would be affected by the uncertainties of society, medical technology development, health care system, and other unexpected events.

Prolonging LE and HALE can be achieved by improving economic development and investment in medical services. However, the prolongation of life does not mean improved quality of life. While striving to improve LE and HALE, we should pay more attention to reducing GAP to improve quality of life. Whether it is the current state or the future forecast trend, most countries' LE, HALE, and GAP are increasing. Governments should provide universal free access to high-quality health care services. They should also provide accessible public health services. Underdeveloped countries and regions should improve the health infrastructure construction and increase health workforce input. As more developed regions continue to increase and improve sanitation facilities, they should formulate more effecting disease prevention and control systems and post-illness care protection systems for communities and families [27]. Some findings suggest that promotion of a healthy lifestyle would help to reduce the health care burdens through lowering the risk of developing multiple chronic diseases, including cancer, cardiovascular disease, and diabetes, and extending disease-free life expectancy [28,29].

People should pay more attention to changing for healthy lifestyle, reasonable diet, moderate exercise, quiting smoking, limiting alcohol intake, and good mental health. The impact of aging and increasing chronic diseases on the extension of the life span is increasing. Countries with the highest life expectancy need to assist their elderly people to spend years in later life with good health. In some countries, LE and HALE might show a decreasing trend in the future. They need to take actions to prevent this. In the future, while striving to improve LE and HALE, more efforts should be made to reduce GAP to improve quality of life.

\section{CONCLUSIONS}

Public health as indicated by LE, HALE, and GAP has improved in most countries and regions in the world since 1995, and it likely will continue to improve in the future. Whether the years of life gained are spent in good or poor health and how to narrow the GAP is an important global health issue $[30,31]$. Research shows that considerable amount of years of life lost are due to tobacco use, unhealthy diet, alcohol consumption, and lack of physical activity. Large gains in HALE and decreasing of GAP will only be achieved by changing such risk factors. Public policies and programs are needed to empower people' to have healthy lifestyles and take other actions needed to maintain good health.

\footnotetext{
Acknowledgements: Thanks to the team members who helped us in data collation. We would like to express our
great appreciation to editor and reviewers for their careful work and thoughtful suggestions that have helped improve
this paper substantially.
Funding: This study was funded in part by the National Natural Science Foundation of China (NSFC, Grant
No.91746205, 71673199, and 71473175), and the China Medical Board (Grant No. 16-262).
Authorship contributions: YGW proposed the overall design of the study. XXC, YBH, CJX and YGW wrote the man-
uscript. YBH, XXC and YGW had full access to all the data. XYZ, ZC XMS, LS, YG and HXY assisted the statistical anal-
ysis. PJ, YGW and YFW finalized the manuscript. All authors reviewed and edited the paper.
Competing interests: The authors completed the ICMJE Unified Competing Interest form (available upon request
from the corresponding author), and declare no conflicts of interest.
Additional material
Online Supplementary Document
} 
1 Life expectancy. Available: https://en.Wikipedia.Org/wiki/life_expectancy/. Accessed: 5 Jan 2018.

2 The World Health Report 1997-conquering suffering, enriching humanity. World Health Forum. 1997;18:248-60. Medline:9478137

3 The global goals. Available: https://www.Globalgoals.Org/https://www.Globalgoals.Org/. Accessed: 5 January 2018.

4 Cheung KS, Yip PS. Trends in healthy life expectancy in Hong Kong Sar 1996-2008. Eur J Ageing. 2010;7:257-69. Medline:21212818 doi:10.1007/s10433-010-0171-3

5 Szwarcwald CL, Montilla DER, Marques AP, Damacena GN, Almeida WDS, Malta DC. Inequalities in healthy life expectancy by federated states. Rev Saude Publica. 2017;51 suppl 1:7s. Medline:28591354 doi:10.1590/s15188787.2017051000105

6 Mathers CD, Iburg KM, Begg S. Adjusting for dependent comorbidity in the calculation of healthy life expectancy. Popul Health Metr. 2006;4:4. doi:10.1186/1478-7954-4-4. Medline:16620383

7 Sullivan DF. A single index of mortality and morbidity. HSMHA Health Rep. 1971;86:347-54. Medline:5554262 doi:10.2307/4594169

8 Imai K, Soneji S. On the estimation of disability-free life expectancy: Sullivan' method and its extension. J Am Stat Assoc. 2007;102:1199-211. Medline:26279593 doi:10.1198/016214507000000040

9 Terms defined, global burden of disease. Available: http://www.Healthdata.Org/terms-defined/. Accessed: 12 December 2017.

10 Sepanlou SG, Parsaeian M, Krohn KJ, Afshin A, Farzadfar F, Roshandel G, et al. Disability-adjusted life-years (dalys) for 315 diseases and injuries and healthy life expectancy (HALE) in Iran and its neighboring countries, 1990-2015: Findings from Global Burden of Disease study 2015. Arch Iran Med. 2017;20:403-18. Medline:28745902

11 Tokudome S, Hashimoto S, Igata A. Life expectancy and healthy life expectancy of Japan: The fastest graying society in the world. BMC Res Notes. 2016;9:482. Medline:27793196 doi:10.1186/s13104-016-2281-2

12 Dwyer-Lindgren L, Stubbs RW, Bertozzi-Villa A, Morozoff M, Callender C, Finegold SB, et al. Variation in life expectancy and mortality by cause among neighbourhoods in king county, wa, USA, 1990-2014: A census tract-level analysis for the global burden of disease study 2015. Lancet Public Health. 2017;2:e400-10. Medline:29253411 doi:10.1016/S24682667(17)30165-2

13 Reus-Pons M, Kibele EUB, Janssen F. Differences in healthy life expectancy between older migrants and non-migrants in three European countries over time. Int J Public Health. 2017;62:531-40. Medline:28239745 doi:10.1007/s00038017-0949-6

14 Jagger C, Weston C, Cambois E, Oyen HV, Nusselder W, Doblhammer G, et al. Inequalities in health expectancies at older ages in the european union: Findings from the survey of health and retirement in Europe (share). J Epidemiol Community Health. 2011;65:1030-5. Medline:21471138 doi:10.1136/jech.2010.117705

15 Mackenbach JP, Karanikolos M, McKee M. The unequal health of Europeans: Successes and failures of policies. Lancet. 2013;381:1125-34. Medline:23541053 doi:10.1016/S0140-6736(12)62082-0

16 Pope CA III, Ezzati M, Dockery DW. Fine particulate air pollution and life expectancies in the united states: The role of influential observations. J Air Waste Manag Assoc. 2013;63:129-32. Medline:23472296 doi:10.1080/10962247.2013 .760353

17 Zhao L, Zhang XY, Bai GY, Wang YG. Violence against doctors in China. Lancet. 2014;384:744. Medline:25176545 doi:10.1016/S0140-6736(14)61436-7

18 Njom Nlend AE, Motaze ACN, Sandie A, Fokam J. HIV-1 transmission and survival according to feeding options in infants born to hiv-infected women in Yaoundé, Cameroon. BMC Pediatr. 2018;18:69. Medline:29458337 doi:10.1186/ s12887-018-1049-3

19 Bennett JE, Li G, Foreman K, Best N, Kontis V, Pearson C, et al. The future of life expectancy and life expectancy inequalities in England and Wales: Bayesian spatiotemporal forecasting. Lancet. 2015;386:163-70. Medline:25935825 doi:10.1016/S0140-6736(15)60296-3

20 Guzman-Castillo M, Ahmadi-Abhari S, Bandosz P, Capewell S, Steptoe A, Singh-Manoux A, et al. Forecasted trends in disability and life expectancy in England and Wales up to 2025: A modelling study. Lancet Public Health. 2017;2:e30713. Medline:28736759 doi:10.1016/S2468-2667(17)30091-9

21 Chateau D, Metge C, Prior H, Soodeen RA. Learning from the census: The socio-economic factor index (SEFI) and health outcomes in Manitoba. Can J Public Health. 2012;103(Suppl 2):S23-7. Medline:23618067 doi:10.1007/BF03403825

22 Sugiura Y, Ju YS, Yasuoka J, Jimba M. Rapid increase in Japanese life expectancy after World War II. Biosci Trends. 2010;4:9-16. Medline:20305339

23 Abdin E, Subramaniam M, Vaingankar JA, Luo N, Chong SA. Measuring health-related quality of life among adults in Singapore: Population norms for the EQ-5D. Qual Life Res. 2013;22:2983-91. Medline:23549857 doi:10.1007/s11136013-0405-X

24 Shim YT, Lee J, Toh MP, Tang WE, Ko Y. Health-related quality of life and glycaemic control in patients with type 2 diabetes mellitus in Singapore. Diabet Med. 2012;29:e241-8. Medline:22507291 doi:10.1111/j.1464-5491.2012.03689.x

25 Sanderson WC, Scherbov S. Faster increases in human life expectancy could lead to slower population aging. PLoS One. 2015;10:e0121922. Medline:25876033 doi:10.1371/journal.pone.0121922

26 Villarreal-Hernández LS, Romo-Martínez JE. Educational status and life expectancy in patients with chronic noncommunicable diseases].[In Spanish]. Rev Med Inst Mex Seguro Soc. 2014;52:316-21. Medline:24878092

27 Hill PS, Buse K, Brolan CE, Ooms G. How can health remain central post-2015 in a sustainable development paradigm? Global Health. 2014;10:18. Medline:24708779 doi:10.1186/1744-8603-10-18 
28 Li Y, Schoufour J, Wang DD, Dhana K, Pan A, Liu X, et al. Healthy lifestyle and life expectancy free of cancer, cardiovascular disease, and type 2 diabetes: Prospective cohort study. BMJ. 2020;368:16669. Medline:31915124 doi:10.1136/bmj.16669

29 Li Y, Pan A, Wang DD, Liu X, Dhana K, Franco OH, et al. Impact of healthy lifestyle factors on life expectancies in the us population. Circulation. 2018;138:345-55. Medline:29712712 doi:10.1161/CIRCULATIONAHA.117.032047

30 GBD 2017 DALYs and HALE Collaborators. Global, regional, and national disability-adjusted life-years (DALYs) for 359 diseases and injuries and healthy life expectancy (hale) for 195 countries and territories, 1990-2017: A systematic analysis for the global burden of disease study 2017. Lancet. 2018;392:1859-922. Medline:30415748 doi:10.1016/ S0140-6736(18)32335-3

31 Steel N, Ford JA, Newton JN, Davis ACJ, Vos T, Naghavi M, et al. Changes in health in the countries of the uk and 150 english local authority areas 1990-2016: A systematic analysis for the global burden of disease study 2016. Lancet. 2018;392:1647-61. Medline:30497795 doi:10.1016/S0140-6736(18)32207-4 